e-journal Keperawatan (e-Kp) Volume 7 Nomor 1, Februari 2019

\title{
HUBUNGAN MEKANISME KOPING DENGAN KECEMASAN PADA MAHASISWA SEMESTER III PROGRAM STUDI ILMU KEPERAWATAN FAKULTAS KEDOKTERAN YANG AKAN MENGIKUTI PRAKTEK KLINIK KEPERAWATAN
}

\author{
Adelina Sumoked \\ Ferdinand Wowiling \\ Sefti Rompas \\ Program Studi Ilmu Keperawatan Fakultas Kedokteran \\ Universitas Sam Ratulangi \\ Email : sumokedadel@gmail.com
}

\begin{abstract}
The Students that would do clinical practice generally have varying levels of anxiety, starting from no anxiety, light, medium, and serious. The coping mechanisms is medhid for resolve the stressed and anxiety. Aimed research to determine whether there is a correlation of coping mechanisms with anixiety to regular semester III Nursing Science Program Faculty Of Medicine who will attend nursing clinical practice. The sample used is total sampling that is 73 samples. The research method used descriptive analytic with cross sectional study approach.Result, research with chi-square statistic test showed that there was correlation beetwen coping mechanisms with anxiety to regular semester III Nursing Science Program Faculty Of Medicine who will attend nursing clinical practice with $p=0,000$. Conclusion the majority of nursing students of regular semester III of Sam Ratulangi University of Manado have a coping mechanisms of adaptive and anxiety level measurable with there is correlation of coping mechanisms with anxiety to regular semester III Nursing Science Program Faculty Of Medicine will attend nursing clinical practice.
\end{abstract}

Keywords : Coping Mechanisms, Anxiety

\begin{abstract}
Abstrak :Mahasiswa yang akan melakukan praktek klinik umumnya memiliki variasi tingkat kecemasan mulai dari tidak ada cemas, ringan, dan sedang, hingga berat. Mekanisme koping merupakan cara mengatasi stress dan kecemasan dengan memperdayakan diri. Tujuan Penelitian untuk mengetahui hubungan mekanisme koping dengan kecemasan pada mahasiswa semester III Program Studi Ilmu Keperawatan Fakultas Kedokteran yang akan mengikuti praktek klinik keperawatan terpadu sampel yang digunakan adalah total sampling yaitu 73 sampel. Metode penelitian menggunakan deskriptif analitik dengan pendekatan cross sectional study. Hasil penelitian dengan uji statistik chi-square didapatkan ada hubungan mekanisme koping dengan kecemasan pada Mahasiswa Semester III Program Studi Imu Keperawatan Fakultas Kedokteran Yang Akan Mengikuti Praktek Klinik Keperawaran Terpadu dengan $\mathrm{P}=0.000$. Kesimpulan mayoritas Mahasiswa Keperawatan Semester III reguler Universitas Sam Ratulangi Manado memiliki mekanisme koping adaptif dan tingkat kecemasan sedang dengan adanya hubungan mekanisme koping dengan kecemasan pada Mahasiswa Semester III Program Studi Imu Keperawatan Fakultas Kedokteran Yang Akan Mengikuti Praktek Klinik Keperawaran Terpadu.
\end{abstract}

Kata kunci: Mekanisme Koping, Kecemasan 


\section{PENDAHULUAN}

UU No. 382014 tentang keperawatan menjelaskan pendidikan professional di Indonesia terdiri atas pendidikan akademik dan pendidikan klinik/profesi ners. Pendidikan keperawatan di Indonesia terdiri dua tahap yang terintegrasi dan tidak terpisahkan yakni pendidikan akademik dan profesi. Pendidikan profesi di lahan praktik rumah sakit bertujuan untuk mengaplikasikan dan menerapkan konsep teori sehingga mahasiswa dituntut lebih aktif dalam tindakan agar terampil dan mampu berpikir kritis dalam pengambilan keputusan klinis (Asosiasi Institusi Pendidikan Ners Indonesia, 2015).

Mahasiswa yang akan melakukan praktek klinik umumnya memiliki variasi tingkat kecemasan mulai dari tidak ada cemas, ringan, dan sedang, hingga berat. Kecemasan yang sering terjadi pada mahasiswa berhubungan dengan praktek klinik keperawatan terpadu seperti rasa cemas karena adanya hal-hal yang berbeda yang belum pernah dilakukan sebelumnya seperti berpindah lokasi dari tempat yang satu ketempat yang lain. Cemas merupakan perasaan tidak nyaman atau kekhawatiran yang samar disertai respon otonom (sumber sering kali tidak spesifik atau tidak diketahui oleh individu) perasaan takut yang disebabkan oleh antisipasi terhadap bahaya (Huda dan Hardhi, 2015 ).

Kecemasan dapat mempengaruhi hasil yang akan diperoleh mahasiswa terutama kecemasan sedang hingga panik. Karena semakin tinggi level kecemasan maka perlu adanya mekanisme koping yang di gunakan individu dalam mengatasi kecemasan yang terjadi. Ketika mahasiswa mengalami kecemasan, maka individu akan menggunakan berbagai mekanisme koping untuk mengatasi cemas seperti kemampuan individu, dukungan sosial, aset material, keyakinan positif individu. Apabila individu tidak mampu mengatasi kecemasan secara konstruktif, maka dapat menjadi penyebab terjadinya perilaku yang patologis (Stuart, 2013).
Mekanisme koping merupakan cara mengatasi stress dan kecemasan dengan memperdayakan diri. Individu biasanya menghadapi kecemasan menggunakan mekanisme koping yang berfokus pada masalah, mekanisme koping yang berfokus pada kognitif, dan mekanisme koping yang berfokus pada emosi. Koping dapat diidentifikasi melalui respon manifestai (tanda dan gejala) koping dapat dikaji melalui beberapa aspek yaitu fisiologis dan psikologis koping yang efektif menghasilkan adaptif sedangkan yang tidak efektif menyebabkan maladaptif (Stuart, 2013).

Tahap Praktek klinik keperawatan mahasiswa semester III berdasarkan kurikulum akademik merupakan tahun kedua mengikuti praktek klinik keperawatan terpadu. Pengetahuan, keterampilan dan kepercayaan diri dari mahasiswa harus ditingkatkan lagi karena dalam proses pembelajaran klinik mahasiswa akan berhadapan langsung dengan keadaan rumah sakit, puskesmas, atau komunitas. Dalam praktik keperawatan, mahasiswa yang praktik akan dinilai sama dengan perawat yang bertugas langsung ditempat praktek keperawatan oleh masyarakat. Sebagian masyarakat tidak akan mencari tahu tingkatan dari mahasiswa, dalam pandangan masyarakat bahwa mahasiswa semester awal dan perawat senior tetap sama yaitu tenaga kesehatan dan memiliki kemampuan khusus. Maka mahasiswa yang baru kedua kalinya mengikuti praktek klini keperawatan harus mampu menguasai teori, punya keterampilan dan lebih percaya diri.

Studi pendahuluan telah dilakukan peneliti pada Mahasiswa Program Studi Ilmu Keperawatan Fakultas Kedokteran Universitas Sam Ratulangi pada tanggal 27 september 2018 dengan teknik wawancara pada 10 mahasiswa, menyatakan bahwa merasa khawatir, takut, dan cemas karena akan diperhadapkan dengan praktek klinik yang penilaiannya akan dapat menentukan hasil pada nilai ujian ahir semester selain 
itu dalam praktik klinik keperawatan mahasiswa harus beradaptasi dengan keadaan rumah sakit, puskesmas atau lingkungan yang baru di dalamnya ada pasien, keluarga pasien, perawat ruangan dan tim kesehatan lainnya. Yang akan memberikan penilaian diantaranya penanggung jawab praktik mahasiswa di lahan praktek (Clinical Instrumenture/ CI) dan Pembimbing dari Istitusi (Clinical Teacher/ CT) dengan kriteria evaluasi absen kelahadiran $100 \%$, kasus: target $30 \%$, laporan askep 30\%, seminar kelompok $20 \%$ dan keaktifan pre-post confedence $\quad 20 \% \quad$ (Psik Fk Unsrat).Berdasarkan latar belakang di atas untuk itu peneliti tertarik ingin melakukan penelitian tentang hubungan mekanisme koping dengan kecemasan pada mahasiswa yang akan mengikuti praktek klinik keperawatan terpadu.

\section{METODE PENELITIAN}

Penelitian ini adalah penelitian kuantitatif dengan jenis non eksperimen (observasional) dengan metode penelitian deskriptif analitik. Penelitian ini menggunakan rancangan penelitian cross sectional. Penelitian ini dilakukan di Program Studi Ilmu Keperawatan Fakultas Kedokteran Unsrat Manado pada bulan Oktober-November 2018 dengan populasi sebanyak 73 responden. Pengambilan sampel pada penelitian ini mengunakan total sampling, yaitu teknik pengambilan sampel dengan mengambil keseluruan angota populasi untuk dijadikan sampel atau responden. Sampel yang digunakan dalam penelitian ini adalah keseluruan mahasiswa semester III Program Studi Ilmu Keperawatan Fakultas Kedokteran Universitas Sam Ratulangi.

Penelitian ini menggunakan instrument mekanisme koping dengan jumlah pertanyaan sebanyak 20 butir dan diinterpretasikan menjadi adaptif jika lebih atau sama dengan nilai yang dihitung menggunakan rumus cut-off point dan maladaptif jika nilai kurang dari cut-off point. Untuk instrument kecemasan yang digunakan dalam penelitian ini adalah Hamilton Anxiety Rating Scale (HARS) Pada instrument ini terdapat 14 gejala yang diobservasi.

Jenis data yang digunakan pada penelitian ini adalah data primer dan data sekunder. Data primer adalah data yang diperoleh langsung dari responden dan data sekunder data yang diperoleh dari pihak Program Studi Ilmu Keperawatan Fakultas Kedokteran Universitas Sam Ratulangi. Pengolahan data yang diperoleh dari hasil penelitian ini diolah secara manual dengan mengelompokan hasil dari lembar kuesioner yang dibagikan dan selanjutnya dilakukan analisis menggunakan uji statistik. Setelah itu diolah menggunakan system komputerisasi, tahap-tahap tersebut yaitu Editting, Coding, Data entry, dan Cleaning.

Analisis univariat pada penelitian ini akan menghasilkan distribusi frekuensi yang menjelaskan atau mendeskripsikan setiap variabel penelitian yaitu mekanime koping dengan kecemasan. Analisis bevariat merupakan analisis hasil dari variabel independen diduga memiliki hubungan dengan variabel dependen. Analisis yang digunakan adalah hasil tabulasi silang. Untuk menguji hipotesa dilakukan analisis statistik dengan uji chi square dengan tingkat kepercayaan 95\% derajat kemaknaan $\alpha=0,05$. Berdasarkan hasil uji hipotesis dengan menggunakan uji Chi Square menunjukkan adanya hubungan mekanisme koping dengan kecemasan pada mahasiwa semester III program studi ilmu keperawatan fakultas kedokteran yang akan mengikuti praktek klinik keperawatan terpadu . 


\section{HASIL dan PEMBAHASAN}

Tabel 1. Distribusi frekuensi mekanisme koping mahasiswa semester III program studi ilmu keperawatan FK Unsrat

\begin{tabular}{lll}
\hline $\begin{array}{l}\text { Mekanisme } \\
\text { koping }\end{array}$ & n & \% \\
\hline Adaptif & 43 & 58,9 \\
Maladaptif & 30 & 41,1 \\
\hline Total & $\mathbf{7 3}$ & $\mathbf{1 0 0}$
\end{tabular}

Sumber: Data primer, 2018

Hasil penelitian menunjukan bahwa dari 73 responden sebagian besar mahasiswa memiliki mekanisme koping adaptif dengan jumlah 43 mahasiswa (58, 9\%) dan sisanya memiliki mekanisme koping maladaptif.Mekanisme koping dapat dipelajari sejak awal timbulnya stresor dan mahasiswa akan menyadari dampak dari stresor tersebut. Kemampuan koping dari individu tergantung dari temperamen, persepsi, dan kognisi serta latar belakang budaya atau norma dimana dia dibesarkan (Setyaningsih, 2012).Mekanisme koping adaptif dapat mendukung fungsi integrasi, pertumbuhan belajar untuk mencapai tujuan dimana dapat ditandai dengan mampu berbicara dengan orang lain, dapat memecahkan masalah dengan afektif, dan dapat melakukan aktifitas konstriktif dalam menghadapi stressor, sedangkan mekanisme koping maladaptif dapat menghambat fungsi integrasi, menurunkan otonomi dan cenderung menguasai sepertihanya bekerja berlebihan, menghindar atau kehilangan kendali (Stuart, 2013).

Tabel 2.Distribusi frekuensi kecemasan mahasiswa semester III program studi ilmu keperawatan FK Unsrat

\begin{tabular}{lll}
\hline Kecemasan & n & $\mathbf{\%}$ \\
\hline Cemas ringan & 13 & 17,8 \\
Cemas sedang & 47 & 64,4 \\
Cemas berat & 13 & 17,8 \\
\hline Total & $\mathbf{7 3}$ & $\mathbf{1 0 0}$
\end{tabular}

Sumber: Data primer, 2018

Hasil penelitian menunjukan bahwa dari 73 responden sebagian besar mahasiswa memiliki kecemasan sedang dengan jumlah 47 mahasiswa (64\%). Tingkat kecemasan sedang memungkinkan seseorang memusatkan perhatian hanya kepada suatu hal yang dianggap penting dan mengesampingkan hal lain tetapi dapat menerima arahan dari orang lain. Manifestasi yang dapat dirasakan yaitu kelelahan yang meningkat, ketegangan otot, lahan persepsi menyempit, mampu belajar namun tidak optimal, konsentrasi menurun, perhatian selektif, emosi tidak stabil seperti mudah menangis, mudah marah, mudah tersinggung, mudah lupa, dan tidak sabar (Anissa, 2018).

Menurut peneliti mahasiswa yang akan mengikuti praktik klini keperawan terdapat fenomena yang memicu terjadinya kecemasan tersebut antaralain dipengaruhi dengan keadaan tempat praktek yang berdeda dengan dunia perkuliahan, hal yang tak biasa dilakukan dalam proses perkuliahan akan dilakukan dalam praktek keperawatan. Lingkungan dan situasi, seseorang yang berada di lingkungan asing ternyata lebih mudah mengalami kecemasan disbanding bila dia berada di lingkungan yang biasa dia tempati. Kecemasan yang muncul pada mahasiswa juga bisa karena kurangnya praktek dalam proses pembelajaran sebelum melakukan praktek klinik keperwatan.

Tingkat awal mahasiswa akan mengalami masa adaptasi dari lingkungan sekolah ke lingkungan perkuliahan, terkait dengan jadwal perkuliahan seperti tugas, kuliah, tutorial dan skill lab yang padat dan baru dirasakan pertama kali setelah memasuki dunia perkuliahan, sedangkan pada mahasiswa yang tingkat akhir sudah mampu beradaptasi dengan lingkungan dan perkuliahan sehingga membantu mahasiswa dalam proses pembelajaran. Individu yang memiliki mekanisme koping positif (adaptif) dan efektif maka dapat meredakan atau menghilangkan stres, sebaliknya jika mekanisme koping yang negatif (maladaptif) dan tidak efektif akan memperburuk kesehatan dan memperbesar potensi terjadinya sakit (Rafiki, 2017). 
Tabel 3.Hubungan mekanisme koping dengan kecemasan pada mahasiswa semester III program studi ilmu keperawatan FK Unsrat

\begin{tabular}{|c|c|c|c|c|c|}
\hline \multirow{2}{*}{$\begin{array}{c}\text { Mekanisme } \\
\text { koping }\end{array}$} & \multicolumn{3}{|c|}{ Kecemasan } & \multirow{2}{*}{ Total } & \multirow{2}{*}{$\mathbf{P}$} \\
\hline & Ringan & Sedang & Berat & & \\
\hline Adaptif & 12 & 30 & 1 & 43 & \multirow{2}{*}{0,000} \\
\hline Maladaptif & 1 & 17 & 12 & 30 & \\
\hline Total & 13 & 47 & 13 & 73 & \\
\hline
\end{tabular}

Sumber: Data primer, 2018

Berdasarkan hasil uji hipotesis dengan menggunakan uji Chi Square (X2) dengan tingkat kepercayaan $95 \%(\alpha 0,05)$, menunjukkan adanya hubungan mekanisme koping dengan kecemasan pada mahasiwa semester III program studi ilmu keperawatan fakultas kedokteran yang akan mengikuti praktek klinik keperawatan terpadu . Dimana nilai $\mathrm{p}=$ $0,000<\alpha=0,05$. Responden terbanyak dalam penelitian adalah mahasiswa yang mengunakan mekanisme koping adaptif dengan kecemasan sedang yang berjumlah 30 mahasiswa (69\%). Menurut penelitian yang dilakukan oleh Rahmawati (2016) yaitu mereka yang memiliki mekanisme koping baik mengambil keputusan dan melakukan tindakan yang tepat saat situasi kritis dan mendesak dan dapat dengan mudah mengendalikan stresor.

Koping yang digunakan pada setiap mahasiswa Keperawatan FK Unsrat dalam menghadapi kecemasan ini berbeda-beda tergantung pada kemampuan menyelesaikan masalah tersebut. Jika masalah tersebut tidak dapat diselesaikan dengan baik maka mahasiswa tersebut akan marah-marah, frustasi hingga depresi, sedangkan jika masalah tersebut dapat diselesaikan dengan baik maka akan memacu mahasiswa untuk belajar dan lebih berkreatifitas, sehingga dapat melahirkan cikal bakal yang kreatif dan kompeten dalam profesi keperawatan. Meskipun jumlah responden yang mempunyai mekanisme koping maladaptif prosentasenya lebih sedikit, akan tetapi tetap memerlukan perhatian dari para pendidik (Wijayanti,2015).
Mekanisme koping adaptif yang digunakan oleh responden mampu menghasilkan kebiasaan baru dan perbaikan dari situasi serta masalah yang dihadapi seperti halnya mekanisme koping adaptif yang digunakan oleh respon dengan supresi dengan pendekatan proses pengendalian diri yang terang-terangan ditujukan menjaga agar impuls-impuls dan dorongan-dorongan yang ada tetap terjaga (mungkin dengan cara menahan perasaan itu secara pribadi tetapi mengingkarinya secara umum). Individu sewaktu-waktu mengesampingkan ingatan-ingatan yang menyakitkan agar dapat menitik beratkan kepada tugas, ia sadar akan pikiran-pikiran yang ditindas (supresi) tetapi umumnya tidak menyadari akan dorongan-dorongan atau ingatan yang ditekan (Mulyadi,2014).

Penelitian yang dilakukan Suminarsis (2009) dengan judul penelitian Hubungan Antara Tingkat Stres Dengan Mekanisme Koping Pada Mahasiswa Keperawatan Menghadapi Praktek Belajar Lapangan Di Rumah Sakit. Menyatakan bahwa semakin tinggi tingkat kecemasan/stres mahasiswa, maka mahasiswa yang akan melaksanakan praktik belajar lapangan di rumah sakit cenderung ke maladaptif.Penelitianyang telah dilakukan terdapat responden yang dengan mekanisme koping maladaptif dengan kecemasan ringan sebanyak 1 responden dan 1 responden dengan koping adaptif memiliki kecemasan berat. Dalam teori yang dikembangkan oleh Spielberger bahwa kecemasan yang dirasakan dipengaruhi oleh Trait Anxiety (kecemasan dasar ) dan Stale Anxiety (kecemasan sesaat). Kecemasan sesaat merupakan peningkatan kondisi kecemasan ataupun kestabilan individu terhadap keadaan yang mengancam baik secara objektif berbahaya ataupun tidak. Kecemasan sesaat dapat dengan mudah hilang dan muncul kembali walaupun seseorang telah menggunakan mekanisme koping yang baik hal ini dapat memicu terjadinya kecemasan yang cukup berat pada saat-saat tertentu sebaliknya dengan 
seseorang yang seseorang yang sumber kopingnya buruk bisa mengalami kecemasan ringan dikarenakan Stale Anxiety (kecemasan sesaat) ini muncul ketika seseorang menerima stimulus dari kejadian lain yang terus terbayang (Mushofa, 2017).Hal ini juga bisa dikarenakan adanya pemikiran yang tidak semestinya oleh seseorang misalnya pemikiran acuh terhadap suatu keadaan dan hanya melakukan hal yang akan lebih memperburuk namun tidak memiliki rasa tanggung jawab.

Penelitian ini terdapat 12 mahasiswa (40\%) yang mengunakan mekanisme koping maladaptif dengan tingkat kecemasan berat dan 17 mahasiswa $(56,7 \%)$ menggunakan mekanisme koping maladaptif dengan tingkat kecemasan sedang. Hal ini dikarenakan pada situasi atau lingkungan yang baru dihadapi oleh individu yaitu saat pertama kali responden melaksanakan praktik ruangan baru, dimana responden melaksanakan prakti sesuai jadwal yang telah di tentukan institusi dengan mengikuti rotasi ruangan tiap dua minggu. Koping merujuk pada pengatasan suatu situasi yang menimbulkan ancaman terhadap individu sehingga mengatasi perasaan tidak nyaman seperti anxietas, rasa takut, berdukadan rasa bersalah sedangkan koping maladaptif dapat menghambat fungsi integrasi, menurunkan otonomi dan cenderung menguasai sepertihalnya bekerja berlebihan, menghindar atau kehilangan kendali (Stuart,2013). Koping maladaptif dari segelintir orang dapat memberikan dampak buruk bagi lingkungan teman sekitarnya dan yang lebih penting lagi akan menghambat proses akademik. Oleh karena itu, penting kiranya para pendidik mengenal tanda-tanda jika terjadi gejala stres/kecemasan meskipun masih dalam tingkatan ringan. Pendidik tidak hanya memberikan materi saja tapi juga dituntut mampu melakukan komunikasi dua arah untuk memberikan arahan dan sharing dengan mahasiswa.

\section{SIMPULAN}

Hasil dari penelitian tentang hubungan mekanisme koping dengan kecemasan Mahasiswa Semester III Program Studi Ilmu Keperawatan Fakultas Kedokteran Universitas Sam Ratulangi yang akan mengikuti praktek klinik keperawatan, bahwa sebagian besar responden memiliki mekanisme koping adaptif, dengan sebagian besar responden memiliki kecemasan sedang. Ada hubungan mekanisme koping dengan kecemasan pada Mahasiswa Semester III Program Studi Ilmu Keperawatan Fakultas Kedokteran Universitas Sam Ratulangi.

\section{DAFTAR REFERENSI}

AIPNI. (2015).Kurikulum Inti Pendidikan Ners. Jakarta: Asosiasi Institusi Pendidikan Ners Indonesia

Anissa, L. (2018). Tingkat Kecemasan Mahasiswa Keperawatan Dalam Menghadapi Ujian Berbasis Computer Based Test Fakultas Keperawatan Universitas Padjadjaran Bandung

Huda,A. dan K, Hardhi. (2015). Aplikasi Asuhan Keperawatan Berdasarkan Diagnosa Medis \&Nanda Nic Noc. Jogjakarta: MediAction.

Mulyadi, E. (2014). Hubungan Mekanisme Koping Individu Dengan Kecemasan Komunikasi Interpersonal Pada Mahasiswa NersProgram Studi Ilmu Keperawatan UNIJA Sumenep. Naskah Publish

Mushofa, M. (2017). Sumber Stres Dan Mekanisme Koping Mahasiswa Keperawatan Universitas Islam Negeri Syarif Hidayatulla Jakarta Dalam Bembelajaran Klinik. Naskah Publish

Rahmawati. (2016). Hubungan Kecerdasan Emosianal Dengan Mekanisme Koping Pada Mahasiswa Tahun Pertama Program Studi Ilmu Keperawatan Universitas 
e-journal Keperawatan (e-Kp) Volume 7 Nomor 1, Februari 2019

Muhammadiyah Yogyakarta. Karya Tulis Ilmiah.

Rafiki, D. (2017). Hubungan Tingkat Kecemasan Dengan Mekanisme Koping Menghadapi Objective Structured Clinical Examination (Osce) Mahasiswa Semester II Stikes Jenderal Achmad YaniYogyakarta. Karya tulis ilmiah

Setyaningsih, D. (2012). Mekanisme Koping Remaja Dalam Menghadapi Sindrom Premenstruasi di SMA N 1 Sokaraja. Naskah Publish.

Stuart, G. W. (2013). Buku Saku Keperawatan Jiwa. Edisi 5. Alih Bahasa Ramona P. Kapoh \& Egi Komara Yudha. Jakarta: EGC.

Suminarsis, T. (2009). Hubungan Antara Tingkat Stres Dengan Mekanisme Koping Pada Mahasiswa Keperawatan Menghadapi Praktek Belajar Lapangan Di Rumah Sakit. FIK UMS Jln A Yani Tromol Post 1 Kartasura. Naskah Publish

Undang-Undang Republik Indonesia Nomor 38 Tahun 2014 Tentang Keperawatan

Wijayanti, E. (2017). Hubungan Tingkat Kecemasan Dengan Mekanisme Koping Mahasiswa Semester II DIIIKeperawatan Dalam Menghadapi Praktek Klinik Keperawatan Di Universitas Nusantara PGRI Kediri. Naskah Publish 